\title{
ABO blood group and social class: a prospective study in a regional blood bank
}

\author{
Cecily Kelleher, Jacqueline Cooper, Detta Sadlier
}

Abstract

Study objective-The aim of the study was to investigate an association previously reported in a retrospective study between the A phenotype and social classes I and II.

Design-The study was a prospective survey using a cohort of blood donors.

Setting-Participants were donors at a regional blood bank in southern Ireland servicing a population of $\sim 380000$.

Participants-Of 2442 donors considered for inclusion in the study, 21 refused to participate, 33 provided insufficient information, and 184 were excluded because they were not wholly of Irish extraction, leaving a total of 2204 subjects, $64 \%$ of whom were male.

Measurement and results-Occupation, age and birth place were obtained from a short questionnaire given to all potential donors during the study period. Social class was defined according to the United Kingdom Registrar General's criteria. No association between the $A B O$ phenotype and social class could be found, either on the whole sample, or on currently employed persons, or on separate analysis of the sexes.

Conclusions-The balance of current evidence is against a variation in ABO distribution by social class designation.

It is well established that differences in $A B O$ blood group distribution exist, both within and between ethnic groups and by geographical area. ${ }^{1}$ The reason for this is unknown but may indicate a protective value in the presence or otherwise of the A or B antigen, either directly or in close association with another as yet unrecognised gene system. A sizeable literature exists on the association between $\mathrm{ABO}$ group and various disease processes, ${ }^{23}$ though no causative mechanism has yet been elucidated.

A social class gradient in the prevalence of many medical conditions is also well recognised, but assumed to relate to socioeconomic circumstance rather than genetic predisposition. ${ }^{4}$ In this context, a recent retrospective study identified an apparent increased prevalence of group $A$ in social groups I and II. The authors went on to postulate a marker status for the $A$ antigen, presumably expressed in both economic prosperity and better health, thus explaining in part the social class association with disease. ${ }^{5}$

However, because of the methodological difficulties associated with retrospective study designs, we determined to re-examine this hypothesis prospectively in an ethnically homogenous population.

\section{Methods}

A regional blood bank in southern Ireland was selected, servicing a population of approximately 380000 . It was estimated, based on a predicted group A phenotype prevalence of $28 \%$ overall in the region and on the expected social class distribution in that cohort of blood donors, that a sample size of 2500 would be sufficient to detect a $3 \%$ increase in prevalence of group A within social classes I and II compared with III, IV and $\mathrm{V}$, and a $9 \%$ increase in social class $\mathrm{I}$ alone compared with the remainder.

A short questionnaire was devised to record date of birth, place of own birth and that of both parents. Current occupation was recorded in detail in accordance with the Registrar General's criteria. $^{6}$ If unemployed, the longest held occupation was recorded. If financially dependent, as in the case of, for instance, full time housewives or students, the occupation of financial supporter was elicited. Data collection was by one of two interviewers, supervised by the donor organiser (DS).

All potential donors (ranging in age from 18 to 65 years) who presented at a session were considered. Each was asked to complete the questionnaire, without reference to blood group record, which was later added. The general purpose, but not the precise hypothesis in question, was known to both donor and interviewer. No donor was excluded and the information was treated as completely confidential. The completed forms were coded by a single observer (CK) before data processing. Statistical analysis was by $\chi^{2}$ method.

\section{Results}

In all, 2442 donors presenting in 35 regular centres were considered. Of these, 21 individuals refused to participate and 33 provided information considered insufficient for accurate coding of occupation. Sixty four per cent of donors were male.

One hundred and eighty four donors were either not Irish by birth or had at least one non-Irish parent. These were excluded from the main analysis and are considered separately. Of the remainder, $82 \%$ were from the Munster region served by the blood bank. The overall blood group phenotype distribution was almost precisely as expected from previous data, with $58.4 \%$ being group $\mathrm{O}, 26.9 \%$ group $A, 12.4 \%$ group B, and $2 \cdot 2 \%$ group AB. ${ }^{7}$ The social class (SC) distribution was as follows: SC I $3.9 \%$, SC II $28 \%$, SC III non-manual $15.7 \%$, SC III manual $25 \cdot 8 \%$, SC IV $19 \cdot 8 \%$, SC V $6.7 \%$.

There was no difference between the sexes in 
Table 1 Distribution of blood group by social class in 2204 Irish subjects. There are no significant differences between groups. $\left(\chi^{2}=5 \cdot 6, d f=15\right.$,
difference $p>0.9)$.

Table 2 Distribution of blood group by social class in 1843 currently employed Irish nationals. No significant differences are seen whether cells are considered singly or in combination as shown. $\left(\chi^{2}=1.5, d f=4, p>0 \cdot 8\right)$.

\begin{tabular}{|c|c|c|c|c|c|c|}
\hline \multirow[b]{3}{*}{ Social class group $\underset{\text { IIIM }+ \text { II }+ \text { IV }+ \text { VMa }}{\text { III }}$} & \multicolumn{5}{|c|}{ Blood group, $\mathbf{n}(\%)$} & \multirow{3}{*}{$\begin{array}{r}\text { Total } \\
598 \\
776 \\
469\end{array}$} \\
\hline & $\mathbf{A}$ & & $\mathbf{B}$ and $\mathbf{A B}$ & $\mathbf{O}$ & & \\
\hline & $\begin{array}{l}164 \\
216 \\
130\end{array}$ & $\begin{array}{l}(27) \\
(28) \\
(28)\end{array}$ & $\begin{aligned} 82 & (14) \\
113 & (15) \\
76 & (16)\end{aligned}$ & $\begin{array}{l}352 \\
447 \\
263\end{array}$ & $\begin{array}{l}(59) \\
(58) \\
(56)\end{array}$ & \\
\hline Total n (\%) & 510 & (28) & $217 \quad(15)$ & 1062 & (58) & 1843 \\
\hline
\end{tabular}

${ }^{a} M, N M=$ manual, non-manual

\section{Discussion}

The data presented here do not support the hypothesis of a variable distribution of the $\mathrm{ABO}$ antigen system in association with social class. The study was designed to collect information prospectively in order to obtain a high degree of accuracy in job description. It was strongly in agreement with the work of Dawson carried out on the Irish population of a generation ago. ${ }^{8} \mathrm{~A}$ negative conclusion in that study was attributed to possible inaccuracy of coding for occupation but this seems unlikely in view of the present findings.

It was decided to use the Registrar General's criteria rather than the Irish socioeconomic group classification $^{9}$ for two reasons. In the first place it was felt to be extremely important that the classification should be as comparable as possible with other studies on the topic. Secondly, the group most likely to be affected were the farmers, who are classified by land valuation in the Irish system. It was not felt appropriate to elicit this type of information at a voluntary donor session, despite the confidential nature of the study. In the event, the farming group comprised only 275 subjects, and a separate analysis of these showed no difference in $\mathrm{ABO}$ blood group distribution from the main data.

The maternal data on birth cohorts of 1958 and $1972^{1011}$ likewise failed to show evidence of a class difference in $\mathrm{ABO}$ group distribution, though these studies had the drawback of being among females only and so subject to the complex problem of classifying financially dependent women. The present study included both sexes and exhibited no differences when these were classified separately, or alternatively by own $v$ financial supporter's employment status.

The reasons for the positive findings of Beardmore and Karimi-Booshehri ${ }^{5}$ remain puzzling. Their retrospective study involved the examination of a large subsample of two regions in England and also derived from blood bank data. Because of the difficulty in interpreting occupational records, especially in women, a large number of subjects had to be disregarded in the analysis. The overall prevalence of group A was in keeping with the population average, though much higher than for an Irish population. However, the class distribution was very unusual, with a considerable overrepresentation of SC V. The likely impact of this is unclear but does make general applicability of their findings difficult. In fact, because of the voluntary nature of blood donation in these islands and the tendency to organise collection through the workplace, one might expect a higher number of SC II and IV donors, which was the case in our own data.

The influence of ethnicity was not satisfactorily explained in that study and may provide a potential explanation of their findings. Examination for instance of surname is not a substitute for assessing place of parents' birth, as was possible in our study. Since all immigrant groups to Britain in the last 150 years have a lower indigenous rate of group $A$ phenotype than native British, one would expect a higher rate of this latter group in the longer established and hence more prosperous classes, rather as seen. Thus, ethnic group would act as a confounder for social class, as seen in the Chilean population where the class gradient was explained by the high prevalence of $A$ in the colonists of Spanish extraction compared with the predominantly $\mathrm{O}$ type native Indians. ${ }^{12}$ The Irish population had no such potential bias, and indeed no change over time was shown, either compared with Dawson's study, or when examining the data by age, a span of 40 years at least.

The relationship between blood group and disease is principally associative, involving for instance geographical trends for a number of common conditions. ${ }^{2}$ Indeed, where group A subjects have been clinically linked with disease, 
the effect has not always been advantageous, as for instance in the increased tendency to thrombosis associated with coronary heart disease. ${ }^{3}$

The ideal way to study a question of this kind is through a random population sample. However, our results are closely in agreement with previous population estimates. $^{8}$

We conclude that $\mathrm{ABO}$ distribution does not vary in relation to social class designation, and that while the possibility of the antigen system acting as a marker for the class gradient seen in disease is an interesting one, there is no clear evidence to support it.

We gratefully acknowledge the help of the Director and staff of the Limerick Blood Transfusion Service.

1 In: Mourant AE, Kopec AC, eds. Northern and Central Europe. In: Distribution of the human blood groups and other polymorphysms. Oxford: Oxford University Press, 1976: 62-9.
2 Mitchell JRA. An association between ABO blood group distribution and geographical differences in death rates. Lancet 1977; i: 295-7.

3 Domaniewska-Sobczak K. Thrombosis, haemorrhage, and other disorders of the circulatory system. In: Mourant AE Kopec AC, eds. Blood groups and diseases. Oxford: Oxford Kopec AC, eds. Blood groups

4 The Black Report: Inequality in health. London: Her Majesty's Stationery Office, 1980

5 Beardmore JA, Karimi-Booshehri K. ABO genes are differentially distributed in socio-economic groups in England. Nature 1983; 303: 522-4.

6 Registrar-General's classification of Occupations. London: Her Majesty's Stationery Office, 1970.

7 Dawson GWP. The frequencies of the $A B O$ and $R h(D)$ blood groups in Ireland from a sample of 1 in 18 of the population. Ann Hum Genet 1964; 28: 49-59.

8 Dawson GWP. The blood group frequencies in some occupational groups in County Dublin. Ann Hum Genet 1958; 22: 315-22.

9 O'Hare A. A note on a proposed census-based Irish social class scale for epidemiological health research. Econ Soc Rev 1982; 13: 205-16.

10 Mascie-Taylor CGN, McManus IC. Blood group and socio-economic class. Nature 1984; 309: 395-6.

11 Golding J, Hicks P, Butler NR. Blood group and socioeconomic class. Nature 1984; 309: 396-7.

12 Valenzuela CY. Bood group and socio-economic class. Nature 1984; 309: 398. 